DON PEDRO DE CARDENAS Y ANGULO. RECTIFICACIÓN Y COMENTARIO

A propósito de dos artículos míos acerca de don Pedro de Cárdenas y Angulo, poeta cordobés, mecenas y primer editor de Góngora, publicados hace algún tiempo en esta revista ${ }^{1}$, ha aparecido un erudito y documentado estudio del profesor Dámaso Alonso, con el título de "Lope, Cárdenas y los Cardemios", en la RFE, 4o (1956) [publicado en 1959], pp. $67-90$.

En los citados trabajos daba yo cuenta de varios nuevos datos sobre la vida y la obra de Cárdenas y Angulo, recogidos principalmente en la Bibliotheca Hispana nova de Nicolás Antonio, no advertidos por los investigadores e historiadores de la literatura española ni por los especialistas de Góngora, al frente de los cuales figura indiscutiblemente Dámaso Alonso, autor de conocidas, admiradas y definitivas obras sobre el poeta de las Soledades. Tuve la fortuna de descubrir, además, la primera poesía firmada con el nombre de Pedro de Cárdenas, y no -según los hallazgos de J. M. Hill- con el pseudónimo poético de "Cardenio", identificado como perteneciente a nuestro Cárdenas por Gallardo, Paredes, Rodríguez Marín y Bell. Fundamentado igualmente en Bell y sus pesquisas, atribuí a Cárdenas y Angulo la paternidad de La Estrella de Sevilla, acatando, en última apelación, el fallo contrario a Lope de Morley y Bruerton (en The chronology of Lope de Vega's "comedias"). Esta conclusión, calificada de convincente por el docto lopista W. L. Fichter, confirma la creencia de Menéndez Pelayo, Bonilla, Wright y otros. Finalmente, llamé la atención sobre otras noticias relativas a nuestro don Pedro procedentes del libro de Paredes y de las cartas de Góngora impresas en la biografía de éste por M. Artigas. Tales noticias adicionaban o rectificaban los informes bio-bibliográficos de los repertorios de Valdenebro y Ramírez de Arellano.

No logré, en cambio, dar con las fechas del nacimiento y de la muerte del poeta-mecenas. Residiendo actualmente fuera de España, me vi imposibilitado de realizar investigaciones en sus archivos y bibliotecas. No me quedaba otro recurso sino deducir suposiciones basadas en los hechos fehacientes de que disponía. Conjeturé así que Cárdenas y Angulo había nacido en 1549 o $155^{0}$. Aquí erré, y deseo rectificar mi equivocación ahora que se conoce la fecha exacta. El futuro amigo de Góngora vino al mundo en los primeros días de septiembre de 1577 , pues fue bautizado el 13 de dicho mes y año. Así lo atestigua la partida de bautismo hallada por el distinguido archivero de Córdoba, don José de la Torre y del Cerro, a instancias de Dámaso Alonso, quien la ha publicado en su artículo². En

1 "Un soneto del autor de La Estrella de Sevilla", NRFH, 7 (1953), 433-438; "Don Pedro de Cárdenas, mecenas y editor de Góngora", ibid., 9 (1955), 22-32. En esos dos articulos se encontrarán referencias bibliográficas que no me ha parecido necesario repetir aquí.

2 Según la partida de bautismo (Alonso, p. 74), "Pedro, hijo de don Hernando Arias de Saavedra y de doña Ana de Caicedo, fue bautizado el 13 de septiembre de 1577 en la parroquia de Santiago (archivo de dicha parroquia, libro $1^{\circ}$ de bautismos, folio 101)". Conocida es la libertad que existía entonces de cambiarse los hijos los apellidos paternos y maternos. Sin embargo, es de notar que Ramírfz dF Arellano, En- 
vista de este descubrimiento, he de desechar la atribución a don Pedro de dos quintillas en elogio de Ercilla, incluidas en los preliminares de La Araucana (1569) y firmadas por un homónimo Pedro de Cárdenas ${ }^{3}$. En cambio, no se ha conseguido exhumar la partida de defunción de nuestro don Pedro. Ramírez de Arellano fijó el fallecimiento en el año de 1645 , sin aducir documento ni razón alguna. Yo llamé la atención sobre el hecho de que Nicolás Antonio relata un episodio en que actúan la viuda y los hijos de Cárdenas y Angulo el año de 1645, de donde se desprende que la muerte del caballero cordobés sobrevino antes de 1645 . Así lo hice presente en mis dos artículos (pp. 196-137 del primero, y p. 27 del segundo), agregando que acaso Ramírez de Arellano conocía ese dato y en él se fundaba. Alonso, que acoge esta noticia mía, coincide con mi suposición y añade (pp. 72-73) un nuevo testimonio: el de Salcedo Coronel, quien, en el segundo tomo de las Obras de don Luis de Góngora comentadas..., a propósito de un soneto de Góngora dedicado a nuestro Cárdenas, hace ver que éste vivía aún. Dicho segundo tomo lleva pie de imprenta de 1645 , pero los preliminares son de 1643 , de suerte que po-

sayo, p. 107 , da como nombres de los padres los de don Pedro de Cárdenas y doña Catalina de Angulo, y sólo designa con el nombre de Fernán Arias de Saavedra a un hermano de nuestro poeta. Hay aquí una confusión, advertida también por Alonso (p. 88, nota 2), aunque no en el Ensayo, sino en otra obra de Ramírez de Arellano: Juan Rufo, jurado de Córdoba, Madrid, 1912, pp. 289-293. Puede resolverse de manera fidedigna gracias al expediente de don Pedro relativo a las pruebas para la obtención del hábito de Santiago, examinado por el mismo Alonso (p. 88) en el Archivo Histórico Nacional de Madrid (Santiago, núm. 1535, año de 16og). Allí constan, declarados por el hijo, los nombres verdaderos de sus padres, "don Hernán d'Arias de Saabedra y Caycedo y doña Ana de Saabedra y Caycedo", y los de sus abuelos paternos, "don Pedro de Cárdenas y doña Catalina de Angulo". Se ve, pues, que Ramírez de Arellano confundió los nombres de los abuelos con los de los padres. Alonso copia, además, de la declaración de uno de los testigos: "que Hernandarias Saavedra y Caicedo, padre del pretendiente, cambió de nombre al casarse; antes de casado se llamaba don Juan de Angulo de Cárdenas".

${ }^{3}$ Ya expresaba yo mis dudas, al escribir: "Es notable que, siendo tan joven, fuera conocido su nombre lo bastante para que se publicase una poesía suya en una obra como La Araucana". El autor de las quintillas en elogio de Ercilla puede ser, según Alonso (p. 77), el mismo que escribió otras dos quintillas para la Historia y relación verdadera... de López de Hoyos, impresa en Madrid el mismo año de 1569; yo también lo creo probable. ¿No será ese Pedro de Cárdenas el abuelo de nuestro Cárdenas y Angulo? Se sabe que testó en 1580 (Alonso, p. 89 nota). - Aprovecho este lugar para dar cuenta de un soneto "de don Pedro de Cárdenas", descubierto por la señora Margit Frenk Alatorre en las Rimas varias en alabança del nacimiento del principe N. S. Don Balthazar Carlos Domingo, que publicó Vicente de Guzmán Suares en Oporto, 1630 (ejemplar único en la H. S. A., reproducido facsimilarmente por A. M. Huntington en tirada de 200 ejemplares). El soneto, dirigido a Guzmán Suares, se halla en el fol. $\S \S 2$ y comienza: "Mientras cantando en verso numeroso...". Por la fecha y por el estilo podría adjudicarse a Cárdenas y Angulo. Sin embargo, sería raro que figurase un poeta español en un librito editado por el poeta portugués, entonces ilustre, Guzmán Suares (cf. el diccionario biográfico Portugal, de Estevez Pereira, t. 6, y Domingo García Peres, Catálogo... de los autores portugueses que escribieron en castellano, Madrid, 189o, pp. 301-304), con la colaboración de un grupo de poetas portugueses. Ese ramillete de poesias en alabanza de un príncipe de España parece compuesto para congraciarse con fines políticos cerca del monarca español que gobernaba a la sazón a Portugal. No se sabe, por otra parte, que Cárdenas y Angulo haya residido en este último país, aunque cabe la posibilidad de que haya sostenido amistad epistolar con Guzmán Suares, quien pudo escogerlo a manera de padrino en la corte de España, donde desempeñaba el cargo de caballerizo de Su Majestad. 
demos pensar -y ésta es otra suposición- que la muerte ocurrió entre 1643 y 1645 . Debo descartar, desde luego, otra suposición mía, que agregué en mi segundo artículo y que adelantaba al año de 1624 la muerte del amigo de Góngora ${ }^{4}$.

Dámaso Alonso ha desentrañado informaciones inéditas acerca de la vida de Cárdenas en el Archivo Histórico Nacional, donde se conservan las pruebas de limpieza de sangre para el ingreso en la orden militar de Santiago. En el expediente mencionado supra, nota 2, hay declaraciones del solicitante y de los testigos, y con base en ellas ha reconstruido Alonso (p. 88) la genealogía de don Pedro ${ }^{5}$.

Con gran diligencia y erudición revela Alonso la existencia de multitud de Cárdenas y de "Cardemos". Foulché-Delbosc había iniciado esta indagación, en la cual topó con ocho "Cardemios" no autores; le siguió Hill, quien tropezó con cinco más, entre ellos un poeta; Bell indicó, además del de Cervantes, tres poetas citados respectivamente por Gálvez de Montalvo, Lope de Vega y Salas Barbadillo, si bien creyó que se trataba de uno solo y que éste era Pedro de Cárdenas y Angulo; Juliá y Morley descubrieron más "Cardemos". Alonso ha ahondado y, al parecer, agotado por ahora esta búsqueda. Ha formado una crecida lista con los ya conocidos y los que él da a conocer (pp. 78-82). Son en total diecisiete "Cardenios" fechables, que aparecen en obras de la época; representan personajes literarios y no corresponden a ningún Cárdenas". Alonso los coloca "en orden aproximadamente cronológico", con los debidos datos bibliográ-

${ }^{4}$ Me fundaba en la muy extraña ausencia de don Pedro de unas fiestas por él organizadas en honor de Felipe IV, celebradas en Córdoba en dicho año. Alonso da cuenta (p. 9o, nota 1) de un documento inédito que nos muestra a Cárdenas en Córdoba en noviembre de 1626, así como del ms. de una Apologia gongorina de Francisco Martínez de Portichuelo, dirigida a don Pedro de Cárdenas y Angulo en 1627 (p. 68). Este ms., conservado en la Biblioteca Provincial de Córdoba (núm. 52), se halla registrado por Ramírez de Arellano en su Ensayo (núms. 714 y 2,592), dato que se nos escapó a todos los investigadores, excepto al sagaz Eugenio Asensio, quien se lo comunicó a Alonso, según hace constar este último (p. 68, nota 1).

s Un pormenor pintoresco: por el testimonio de Cárdenas acerca de su edad se ve que se quitaba hasta diez años, -achaque común entre poetas, según subraya Alonso (p. 74). Recuerdo otro caso semejante, el de Lope de Vcga, quien se descontaba también hasta diez años (A. G. DE AMEzÚ, Lope de Vega en sus cartas, Madrid, 1940, t. 2, p. 257, nota 3; S. G. MorLeY, "The pseudonyms and literary disguises of Lope de Vega", UCPMPh, 33, 1951 , p. 484 , nota 146). Cárdenas reincidió en esa flaqueza al testificar en las pruebas del sobrino de Góngora, don Francisco de Góngora y Argote (Santiago, núm. 3497, año de 1622). Uno de los testigos del expediente de don Pedro declara que es "moço... ágil, que sabe y puede andar al caballo", que se ocupa en ellos muy de ordinario y "que los tiene suyos proprios" (p. 73). De otra noticia se deduce que era muy aficionado a toros y caballos y, en general, a fiestas en que interviniera la equitación (pp. 89-9o). En la Bibliografía de la $N R F H$, núm. 35345 , veo citado el siguiente artículo, que no he leído, y que Alonso no menciona: Još́ María de Cossio, "Un taurino del siglo xvn: don Pedro de Cárdenas y Angulo", Revista Nacional de Educación (Madrid), 1951, núm. 102; BACórd, 25 (1954), 278-286.

"Al final del artículo (p. go), añade Alonso otro "Cardenio", que aparece en un romance de Carrión. - Por otra parte, logra Alonso reunir (pp. 76-78) hasta siete poetas de apellido Cárdenas, que no son don Pedro de Cárdenas y Angulo ni usan el pseudónimo de "Cardenio". Los fecha también, cita alguna de sus poesías, la obra en que se encuentran y los repertorios bibliográficos de donde extrae estas noticias. De uno de ellos, Bernardo Luis de Cárdenas, di cuenta por primera vez ("Un soneto...", p. $43^{8)}$. 
ficos y noticias de interés; brinda razones muy atinadas acerca de ellos, y juzga que el "Cardenio" de Gálvez de Montalvo (1582) no personifica a Cárdenas y Angulo porque éste tenia entonces unos cinco años de edad (p. 82), ni a la misma persona que el "Cardenio" de Lope (La Arcadia, 1958) (p. 86, nota 3). Esto es absolutamente admisible, aunque se puede añadir que el "Cardenio" de La Arcadia puede ser nuestro Cárdenas, puesto que en 1598 contaba veintiún años y desde su juventud se distinguió como poeta, según dice su biógrafo Ramírez de Arellano. Se puede decir asimismo que ese personaje de Lope es un poeta rústico (provinciano) y rico, como Cárdenas y Angulo, en contraste con el "Belardo" de la misma novela, poeta pobre "con poca costa y mucha traza", como Lope En cuanto al "Cardenio" de Salas Barbadillo, prueba Alonso (p. 81, núm. 15) que es el mismo Salas, quien lo usó a manera de pseudónimo en $E l$ caballero puntual (Primera parte, 1614, escrita en 1613), y no puede coincidir con el de Gálvez de Montalvo, porque Salas contaba entonces (1582) apenas un año de edad (p. 82). Por último, al tratar del "Cardenio" de Cervantes (pp. 75-76), se muestra contrario a la opinión de autoridades como Gallardo y Rodríguez Marín y, desde luego, no acepta la de Ramírez de Arellanos.

De los diecisiete "Cardemios" que enumera, entresaca Alonso nueve (pp. 83-86) a los cuales califica de lopescos, es decir, introducidos por Lope en sus comedias, con afinidades suyas, y destaca "la afección especial" de éste hacia el nombre de "Cardenio". Yo me pregunto: ¿no lo habrá derivado del apellido Cardona de su afectuoso amigo el Duque de Sessa? Esto no obsta para que el poeta se lo aplicara a sí mismo. Sigue (pp. 84-85) un fino análisis psicológico del carácter y actuaciones de los "Cardemios" lopescos, comparados con la vida y el alma del Fénix, de donde infiere Alonso que Lope se representó, por lo menos, en algunos de ellos.

Y llegamos al problema de la paternidad de La Estrella de Sevilla. Dámaso Alonso se opone a reconocer a Cárdenas y Angulo como autor de la famosa tragedia. Tampoco la cree de Lope. Aprueba el juicio de Menéndez Pelayo y no duda del resultado del análisis métrico de Morley y Bruerton, aunque, con referencia al estudio de éstos, advierte la posibilidad de que el texto utilizado se halle "sumamente alterado por un refundidor". Opina que debió someterse a igual examen, no sólo el texto de la edición desglosada, sino también el de la edición suelta, e insinúa que algunas de las anomalías de la versificación (con respecto a la habitual de Lope) habrían desaparecido entonces. Esta observación es discreta. Tengo para mí, no obstante, que las variantes entre ambos textos carecen de suficiente alcance para modificar la conclusión de Morley y Bruerton?

\footnotetext{
7 Meńndez Pelayo, Estudios sobre el teatro de Lope de Vega, Madrid, 1921, t. 2 pp. 128-129, dice que La Arcadia "es en parte autobiográfica y rigurosamente histórica... En ella se introdujo el mismo poeta con su acostumbrado nombre pastoril de -Belardo", e introdujo también a muchos de sus amigos". He manejado el ejemplar de la primera edición de La Arcadia que se conserva en la Colección de Ticknor (Boston). La frase "con poca costa y mucha traza" se halla en el fol. $246 \mathrm{v}^{\circ}$. En la H. S. A. hay un ejemplar de 1599, con algunos preliminares de 1598. Menéndez Pelayo (op. cit.) no conocía la fecha de la ed. príncipe, y dio el año de 1602 .

8 Alonso saca a luz otro "Cardenio" de Cervantes, en el cual no se había reparado: el de su comedia La entretenida (1615). Éste caracteriza a un personaje muy distinto, un estudiante apicarado (p. 76, y p. 81, núm. 17).
} 
Alonso llama "gongorista" (p. 67), con buen fundamento, a Cárdenas y Angulo, y ésta es una de las razones en que se basan quienes no lo admiten como autor de La Estrella, en la cual no ven rasgo alguno de gongorismo. Conviene recordar, sin embargo, la autorizada opinión del hispanista Henry Thomas, en el prólogo a su traducción inglesa de esa obra (Newtown, 1935, pp. v-vi): "El autor escribe en un estilo sencillo y directo en las partes meramente narrativas y dramáticas de la pieza; pero cuando se esfuerza en alcanzar un efecto especial en ocasiones más elevadas, se adhiere [relies] al gongorismo entonces reinante... En el texto corto se han suprimido los pasajes gongorinos más abstrusos y absurdos...; por desdicha, las supresiones se hicieron sin cuidado".

El principal argumento que volvió a introducir el nombre de Lope fue el hallazgo hecho por Juliá ${ }^{10}$, en la comedia El Perseo, del personaje "Cardenio", pastor en el cual se retrata el Fénix al poner en su boca estas palabras: "Que una plaza me dé de cormista, / estudio que conviene con mi ingenio"; conocido es, en efecto, el anhelo de Lope por obtener el nombramiento de cronista real. Acerca de los pseudónimos o nombres ficticios del Fénix, además de Juliá, han tratado Ricardo del Arco, J. M. de Cossío y, más recientemente, S. G. Morley en su breve y sólida monografía sobre los "disfraces literarios" de Lope de Vega ${ }^{11}$. Discurre Morley sobre "Cardenio" en las pp. 436-438. Empieza por examinar los "Cardemos" descritos por Foulché-Delbosc y hace notar que la única comedia de Lope indicada, Alejandro el segundo, es de dudosa autenticidad y, en su forma actual, no ciertamente del Fénix ("The pseudonyms...", p. 437; cf. The chronology..., pp. 252-253). En cambio, advierte que el hispanista francés no reparó en cinco comedias lopescas auténticas que contienen "Cardemios": La escolástica celosa (1596-1602), La firmeza en la desdicha (1610-1612), El Marqués de Mantua (1596), El mayorazgo dudoso (1598-1603) y La mocedad de Roldán (1599-1603). El "Cardenio" de la primera es una figura importante, mientras que en las demás representa un papel secundario. En ninguno de ellos encuentra Morley traza de Lope. Empero, en El mayorazgo dudoso, a más del pastor "Cardenio", personaje sin importancia, surge un "Lisardo", galán principal que, disfrazado de jardinero, asume el nombre de "Cardenio", sin que haya

${ }^{0}$ Estos ilustres hispanistas prefirieron la edición más extensa, que cuenta con $5^{26}$ versos más, gracias a los cuales se completan y aclaran varios pasajes de la versión corta, inconclusos unos y sin sentido otros. Es, además, la edición que contiene al final el pseudónimo poético de "Cardenio".

10 Eduardo Julí Martínez, en Obras dramáticas escogidas de Lope de Vega Carpio, t. 2, Madrid, 1934, pp. xxv-xxvi.

11 Ricardo DEL ARCo, La sociedad española en las obras dramáticas de Lope de Vega, Madrid, 1941 (véase la lista de las pp. 150-151); José María de Cossío, Lope, personaje de sus comedias, Madrid, 1948, discurso académico reseñado por S. G. MorLey en $H R$, 18 (1950), 268-269; S. G. MORLEY, "The pseudonyms and literary disguises of Lope de Vega", UCPMPh, 33 (1951), 421-484. Este erudito estudio-citado y comentado con acierto por Dámaso Alonso- representa el trabajo de muchos años de lectura e investigación. Como todos los de Morley, abunda en noticias inéditas y juicios originales $y$ bien cimentados. Además, agota la materia. Agrupa por orden alfabético todos los personajes ficticios en que se retrató Lope. He contado hasta cincuenta y cinco "pseudónimos" correspondientes a las comedias auténticas, y cinco más de las de atribución dudosa. A continuación de cada nombre ofrece Morley los pormenores dramáticos y bibliográficos, y una interpretación y juicio crítico. 
conexión alguna entre él y el verdadero Cardenio ${ }^{12}$; y este "Lisardo-Cardenio" representa posiblemente a Lope. En veintiocho comedias auténticas suyas figura un "Lisardo" ("The pseudonyms...", p. 457), en quien algunos han creído ver otro nombre poético del dramaturgo, si bien Morley no descubre en esos "Lisardos" nada de autobiográfico: todos personifican a un hidalgo o a un noble; sólo uno es criado, y otro labrador. Por otra parte, el mismo Morley (pp. $45^{6-457}$ ) ha dado con "Lisardos" en dos obras no dramáticas del Fénix, en las cuales sí presenta el personaje características inequívocas del poeta. "Lisardo" llamó alguna vez Lope al Duque de Sessa; también le llamó "Lisio" y quizá "Cardenio", incitado, como hemos dicho, por su apellido Cardona ${ }^{13}$.

Para Morley, el "Cardenio" de La Arcadia no tiene nada de Lope (p. 437), como tampoco el resto de los "Cardemios", excepto el del Perseo. Disiente Alonso - coincidiendo con Juliá- en lo tocante al de La escolástica celosa: "Cardenio" - dice (p. 79, núm. 3)- es aquí el protagonista, un estudiante en quien "hay rasgos evidentes del propio Lope". Finalmente, al referirse Morley al "Cardenio" descubierto por Juliá, se muestra en un todo conforme con él y dice que Lope pensaba sin duda en sí mismo cuando expresó, por boca de aquél, el deseo de alcanzar el cargo de cronista. Deduce Morley, al final de su monografía, la imposibilidad de identificar completamente con Lope a ningún personaje ficticio que se encuentre en sus obras, desde el persistente (omnipresent) "Belardo" hasta los efímeros y fugaces "Polifemos", "Pablos" o "Cardemios": no debe aceptarse dicho ni hecho alguno de tales personajes como propios de Lope, a menos que ello se demuestre con otros argumentos, de índole externa (external evidence) ${ }^{14}$.

El caso de La fábula de Perseo (ca. 1611) cumple con tal condición, y prueba que Lope se encarnó por lo menos una vez en un "Cardenio". Mas ello no prueba que Lope escribiera La Estrella de Sevilla. Tanto Morley-Bruerton como Dámaso Alonso niegan que Lope, con el pseudónimo de "Cardenio" o sin él, sea el autor de la famosa tragedia. No es cuestión de un nombre o un pseudónimo; se trata de un problema más hondo; depende del fondo mismo de la pieza, de su estructura y de su estilo. Todo delata a un escritor con las siguientes características: poeta mediano, compositor de estrofas no usadas por Lope, con rimas andaluzas, no improvisador, sino, por el contrario, persona que medita y proyecta

12 Este parece ser -dice Morley- uno de tantos ejemplos de la falta de cuidado de Lope, que solía dar el mismo nombre a dos personas de una misma comedia. Por mi parte, me imagino que el galán, al tomar el nombre del pastor, lo hace para encubrir mejor su verdadera identidad.

13 Como se sabe, el nombre completo del Duque era don Luis Fernández de Córdoba Cardona y Aragón. En la comedia Don Lope de Cardona (donde interviene el dramaturgo con el ya conocido pseudónimo de "Belardo"), defiende Lope a su amigo y protector contra su destierro de la corte en 1611 . Véase el interesante artículo de A. W. Bork, "Lope's Don Lope de Cardona, a defense of the Duke de Sessa", HR, 9 (1941), $348-358$.

${ }_{14}$ Ya habia puesto en guardia a los investigadores J. F. Montesinos (citado por el mismo Morley) contra "la falaz inseguridad de atribuciones basadas en nombres poéticos, posibles alusiones autobiográficas, etc.", dando el ejemplo de la rectificación de unas conjeturas sobre un romance atribuido por error precisamente a Lope de Vega (RFE, 19, 1932, p. 82). 
el plan de su obra, cualidades que no concuerdan con las del Fénix. A la inversa, se ajustan aparentemente a las de don Pedro de Cárdenas y Angulo y al "Cardenio" de La Arcadia. Es justo, sin embargo, admitir que se exijan más convincentes y definitivas pruebas para inclinarse en favor de nuestro Cárdenas. En el caso de que no se comprobara el derecho de éste a nombrarse padre de La Estrella, lo poseería uno de los "Cardemios" sacados a la luz del día por Alonso, o algún otro "Cardenio" que quede por descubrir, ya que el documento más fidedigno llegado hasta ahora a nosotros, o sea el texto de la versión extensa, declara puntualmente, en los versos finales, que "Cardenio" es el autor. Alonso no niega esta posibilidad (p. 86).

Prosíganse, pues, las investigaciones, cuyo campo ha ensanchado Alonso con sus oportunas y valiosas a portaciones. Para ello, ténganse presentes sus advertencias y conclusiones (p. 87): "Cardenio, como nombre poético, no es del todo infrecuente... Parece que los Cárdenas poetas eran muchos... Detrás de todo Cárdenas poeta hay, en potencia, un Cardenio (si bien nos engañariamos pensando que detrás de todo Cardenio ha de haber, por fuerza, un Cárdenas) ${ }^{15}$... Había ... bastantes poetas Cárdenas en Sevilla a principios del siglo xvn; no deja de ser interesante dado el sevillanismo de "La Estrella de Sevilla», obra de un Cardenio" (el subrayado es mío). La condición principal o acaso única que requiere Alonso en el autor de La Estrella es ser sevillano, o haber vivido bastante tiempo en Sevilla.

No se pierda la esperanza. "Quizá algún día -escribe Alonso (p. 71)se descorra el velo que oculta al autor de La Estrella de Sevilla; me extrañaría muchísimo ver aparecer detrás el nombre de don Pedro de Cárdenas y Angulo. En último rigor crítico no puedo negar la posibilidad de que sea él el autor; pero me parece poquísimo verosímil".

He aqui algunas papeletas mías, acaso útiles para las futuras investigaciones. En la Biblioteca Colombina se conserva el ms. de la obra de EnriQue Vaca de Alfaro, Escritores cordobeses ilustres (tomo 72 de "Varios": cf. $B H i, 55,1953$, p. 149 , nota 1). En la B. N. M. se custodia (ms. 3269) la Historia y nobiliario de Córdoba, por Alonso García de MoraLES Y PAdilla, y otro ms. de la misma obra se halla en el Archivo Municipal de Córdoba (cf. BHi, loc. cit.). A la B. N. M. debe haber ido a parar un ms. de don Juan Pérez de Guzmán y Gallo, secretario que fue de la Academia de la Historia, en el cual ofrece un inventario de ocho mil (o doce mil) poetas de los siglos de oro ${ }^{16}$. El ms. inédito de L. Ramírez DE

15 En la p. 9o, abre Alonso una nueva pista para rastrear "Cardemios" en nombres que empiecen con Car-, ya que Cárdenas, Carpio y Carrión los produjeron; en el caso de Lope de Vega, hay que tener en cuenta no sólo el apellido Carpio, sino también, como dejo anotado, el de Cardona.

16 He aquí cómo describe él mismo ese inventario en su libro El autor y los interlocutores de los "Dialogos de la monteria", Madrid, 18go: "Las investigaciones que tengo practicadas respecto a la vida íntima, social y literaria de los doce mil poetas que aproximadamente inundan el Parnaso de España desde principios del siglo xv a fines del siglo xvn, y cuyo inventario por riguroso orden alfabético tengo evacuado y dispuesto..."; y en su Cancionero de la rosa, Madrid, 1891, p. 91: "El número de los que han escrito en versos castellanos durante los siglos xvi y xvn excede de ocho mil poetas, según el Inventario de nombres que tengo formado con presencia de sus escritos'. Si este $\mathrm{ms}$. no se hallare en la B. N. M., estará, sin duda, en posesión de los herederos de Pérez de Guzmán y Gallo, a menos que se guarde en la Academia de la Historia. 
las Casas Deza, Hijos ilustres... de la provincia de Córdoba, se guarda también en la B. N. M. (ignoro la signatura). La Biblioteca Pública de Boston posee, en la Colección de Ticknor, un ms. de La Estrella de Sevilla, del siglo xIx (85 pp.; sign. D.24). Lo he examinado. Parece ser de Gayangos; es copia de la edición corta, y lleva al final el nombre de Lope; convendría confrontar el texto con los de las ediciones impresas ${ }^{17}$.

Para terminar, Alonso toma nota, tácitamente, de mi hallazgo en $\mathrm{Ni}$ colás Antonio de un suceso importante en la vida de Cárdenas y Angulo, cual es el haber publicado la primera edición (typis mandari curavit primus) de las poesías de Góngora, precedidas de un breve pero elegante prólogo en elogio del poeta. Dice Alonso (p. 7o): "El haber protegido [Cárdenas] a Góngora e intervenido personalmente en la primera salida al mundo de las Soledades y el Polifemo, merecen toda nuestra atención".

Doy las más sinceras gracias a mi amigo y antiguo compañero del Centro de Estudios Históricos de Madrid, Dámaso Alonso, por las alabanzas que me dedica, al par que a Aubrey F. G. Bell, al comienzo de su artículo. Si el servicio prestado por los míos no fuera otro que el de haber motivado el suyo, constituiría la mayor satisfacción a que pudiera yo aspirar.

Homero Serís

Centro de Estudios Hispánicos,

Syracuse University.

\section{EL SIMBOLISMO DEL SOL EN LA POESÍA DE FEDERICO GARCIA LORCA}

En otras ocasiones nos hemos referido al carácter cósmico de la poesía de Federico García Lorca, y al puesto preponderante que en ella ocupa la luna con sus ciclos periódicos, su tradición folklórica y astrológica, y su carácter de divinidad mítica que rige con implacable inexorabilidad el destino del hombre ${ }^{1}$. El sol, aunque en menor medida, completa este

17 En la misma Colección existen los siguientes libros: Sancho Ortiz de las Roelas, o La Estrella de Sevilla, tragedia con anotaciones, sin portada, 96 pp., sign. D.147.3 [J. Smallfield Hackney, ca. 1820], y J. C. Zedlitz, Freiherr von, Der Stern von Sevilla, Trauerspiel, Stuttgart und Tübingen, 1830, sign. D.149.1. Según nota manuscrita de Ticknor, esta obra se basa en el "excelente sumario" y fiel traducción inglesa de partes de La Estrella de Sevilla que incluyó Lond Holland en su Life of Lope, t. 1, pp. 155200. También se basó en Lord Holland la escritora y actriz FanNY Kemble (Frances Aun) para su versión inglesa de La Estrella, New York, 1837 (la Kemble fantaseó mucho, y añadió multitud de escenas de su propia inventiva: véase J. P. W. CrawFORD, "An early 19th-century English version of La Estrella de Sevilla", en Estudios eruditos in memoriam de A. Bonilla y San Martin, Madrid, 1930, t. 2, pp. 495-505). La primera traducción inglesa completa y directa es la ya citada de Henry Thomas, basada en ambos textos, y con una excelente introducción, que debe leerse (en la portada se lee: "attributed to Lope de Vega"). Recientemente ha aparecido una nueva traducción al inglés del texto largo, debida a Elizabeth C. Hullihen (Charlottesville, Virginia, 1955), sin introducción ni notas, con el nombre de "Cardenio" al final, pero con el de Lope de Vega Carpio en la portada, como autor.

1 Véase nuestro libro La poesía mítica de Federico Garcia Lorca, Eugene, Oregon, 1957, y mi artículo "El simbolismo de la luna en la poesía de Federico García Lorca", PMLA, 72 (1957), 1060-1084. 